\title{
Making the internal market work: a case for managed change
}

\author{
Lucy Moore, Maureen Dalziel
}

The internal market in the NHS is meant to ensure that provider units compete on the basis of price and quality and that money follows patients into efficient units. But the example of what happened to one local ophthalmology unit suggests what may go wrong when entrepreneurial activity is applied in a market that does not work perfectly. In 1991-2 the unit had a high workload but also comparatively high prices (because of crude pricing in the local hospital); because of pressure of work the waiting times lengthened and general practitioners increasingly complained about the service. The staff in the unit reopened a longstanding debate about the need for a third consultant ophthalmologist, but neither the purchasers (including fundholders) nor the provider unit were able to fund the post. Fundholders in a neighbouring district, however, together with that district health authority, decided to place their contracts elsewhere for the following year. Although the withdrawal of contracts jeopardised the clinical and financial viability of the ophthalmic unit, patients continued to use the service. When general practitioners in the district realised that their local service might collapse they pressed to keep the service open. The fundholders and the host purchaser finally agreed to fund a third consultant and drew up standards for the service. As a result the waiting times fell and the service is now described as "excellent." Short term market decisions may have unforseen long term implications for services to patients. This needs to be addressed as part of the evolution of the reformed NHS.

As we enter the third year of the internal market there are mixed messages about the impact the changes in the NHS have had on the quality and efficiency of health care, and more importantly, what these changes have meant for patients. While there is evidence, for example, that more patients than ever before are being treated, ${ }^{1}$ with reductions in waiting times and more surgery being undertaken on a day care basis, ${ }^{2}$ there is concern that the contracting process has limited patient choice. ${ }^{3}$ There are also concerns that the general practitioner fundholding scheme has created a two tier system, ${ }^{4}$ reducing access to care for some patients.

Our experience in a district health authority on the outskirts of London, with $25 \%$ of the population covered by general practitioner fundholders, provides some insights into the workings of the internal market. With easy access to central London and to several local providers, all anxious to secure a prosperous future, competition between providers is tough. We use the example of the ophthalmology unit to describe how the market has changed the provision of services within the district and to highlight the impact on purchasers, providers, and patients.

Hillizgdon Health Agenc Maureen Dalziel, chief executive

\section{Correspondence to:} Dr M Dalziel, Hillingdon Health Agency, St John's, Kingston, Uxbridge UB8 3PL.
In 1991 the local hospital within the district was still a directly managed unit. In April 1991 the ophthalmology unit within the local hospital agreed "steady state" contracts with the host district, a neighbouring district health authority, and the general practitioner

\section{Service specification for ophthalmology services}

(1) All patients referred by their GP should be accompanied by a letter from the GP which should contain:

A statement of the problem

Relevant medical history

Current medication

Recent blood pressure measurement

Results of recent urine analysis

(2) Emergency patients should be seen on the day of referral. This initial consultation will often be with the senior house officer who will provide treatment and arrange consultant follow up as required by the clinical condition.

(3) Urgent cases should be seen by a consultant within a week of referral.

(4) Routine cases should be seen within eight weeks of referral.

(5) Operations should be performed within twelve weeks of the patient being entered on to the waiting list.

(6) GPs should receive letters about their patients:

Following the first clinic visit

When the patient is discharged from the clinic

When the diagnosis, prognosis, or treatment is changed

Following inpatient treatment

At least every year for patients who attend the clinic

On a long term basis for the monitoring of chronic conditions (for example, glaucoma, diabetic retinopathy)

(7) Letters should be legible and include the following information:

Diagnosis

Treatment performed

Treatment prescribed

Prognosis

fundholders within both districts (table I). By December 1991 staff within the ophthalmology unit, unable to respond to increasing demands from local general practitioners and their patients, had reopened a longstanding debate about the need for a third consultant ophthalmologist.

Simultaneously, in response to increasing complaints from general practitioners and to inform the contracting process for 1992-3, the host district began a review of the population's requirements for ophthalmology services, negotiating with the local hospital to ensure that an assessment of the quality of the service provided by the hospital was part of this process.

\section{Ophthalmology services}

Ophthalmology services provide prevention and treatment for a broad range of disorders of the eye. The diseases affect people at the extremes of age, with the most common disorders occurring in the very young and the old. Cataract, glaucoma, and squint make up $70 \%$ of the inpatient workload. Outpatient treatment is dominated by the long term follow up of patients with chronic disease-for example, glaucoma and diabetes. ${ }^{5}$

From a review of the demography of the population, the epidemiology of ophthalmic disease, and recent 
and predicted developments in technology, the host district concluded that there had been and would continue to be an increasing need for cost effective ophthalmic treatments over the next five years..$^{6-11}$

OPHTHALMOLOGY SERVICE WITH THE LOCAL HOSPITAL

The comparative performance of the ophthalmology department in the local hospital showed a relatively efficient outpatient and inpatient service. The average outpatient workload for new patients per consultant was double the College of Ophthalmologists' recommendations $\mathrm{s}^{12}$ and compared favourably within the region (table II). Although the percentage of patients being treated as day cases was below that recommended by the Audit Commission, ${ }^{13}$ it was in line with the national average.

However, the average waiting time for inpatient care was more than 30 weeks and the waiting time for a new outpatient appointment had risen to 35 weeks. Discussions with the clinicians and staff revealed that they had responded to increasing demands by seeing more and more patients. As a result, they had insufficient time to communicate well with patients or general practitioners and did not meet the standards for training required by their professional body.

There was a clear message. The local service struggled to meet existing demand, and there was evidence of increasing potential need in future. The quality of the service was unsatisfactory. Standards set out in the patients' charter were not being met. ${ }^{14}$ Both general practitioners and those providing the service were unhappy.

Some small changes in the organisation of the service were identified that could be made to improve both the quality and efficiency of the service-for example, an increase in day surgery. However, this review suggested that a shortage of clinical staff was a key factor in explaining the criticisms that had emerged. The department had two consultant ophthalmologists to cover a population of about 280000 . The College of Ophthalmologists recommend one consultant per 80000 population. ${ }^{12}$

As the review progressed it became clear that all the purchasers of the ophthalmology service were anxious

TABLE I-Source of contracted activity (finished consultant episodes) for ophthalmology services within the local hospital

No (\%) of finished consultant episodes

\begin{tabular}{lc}
\hline Host district (A) & $470(48)$ \\
Other district purchaser (B) & $165(17)$ \\
GP fundholder A & $141(15)$ \\
GP fundholder B & $153(16)$ \\
Others & $41(4)$ \\
Total & $970(100)$
\end{tabular}

TABLE II-Summary of activity data for the total ophthalmology department in comparison with national and regional standards

\begin{tabular}{lccc}
\hline & Ophthalmology unit & $\begin{array}{c}\text { College of } \\
\text { Ophthalmologists }\end{array}$ & $\begin{array}{c}\text { Regional } \\
\text { average }\end{array}$ \\
\hline Average No of new patients per clinic & $10 \cdot 1$ & $5-6$ & $3 \cdot 9$ \\
Average total patients per clinic & 40 & $4: 1$ & 25 \\
Ratio of old to new outpatients & $2 \cdot 9: 1$ & $9-20: 1$ & $5 \cdot 5: 1$ \\
Ratio of total outpatients to inpatients & $18: 1$ & & $3: 1$ \\
No of operations per year per consultant & 405 & & 360 \\
\hline
\end{tabular}

TABLE III-Cost per finished consultant episode and day surgery cases in the local ophthalmology unit and closest competitor units

\begin{tabular}{lcccccc}
\hline & $\begin{array}{c}\text { Local } \\
\text { ophthalmology } \\
\text { unit }\end{array}$ & $\begin{array}{c}\text { Unit } \\
\text { A }\end{array}$ & $\begin{array}{c}\text { Unit } \\
\text { B }\end{array}$ & $\begin{array}{c}\text { Unit } \\
\text { C }\end{array}$ & $\begin{array}{c}\text { Unit } \\
\text { D }\end{array}$ & $\begin{array}{c}\text { Unit } \\
\text { E }\end{array}$ \\
\hline $\begin{array}{l}\text { Extra contractual referrals }(f) \\
\text { Day surgery }(f)\end{array}$ & 1605 & 1152 & 1532 & 1200 & 1717 & 1261 \\
$\%$ Day surgery & 599 & 411 & $\begin{array}{c}N^{\star} \\
6 \%\end{array}$ & $\begin{array}{r}450 \\
N^{\star} \\
1 \%\end{array}$ & $\begin{array}{r}469 \\
34 \%\end{array}$ \\
\hline
\end{tabular}

No separate price. to secure changes in the quality of the service before contracts for 1992-3 were agreed. To make these changes both purchasers and providers agreed that a third consultant ophthalmologist was needed. Although this decision was made in March 1992, it was not possible to take immediate action as neither purchasing authorities (including fundholders) nor the provider unit felt that they could take responsibility to fund a third consultant. The apparent relative efficiency of the service had not been reflected in the price.

The price of a finished consultant episode within the local unit was at the upper end of the range. Other nearby units with similar services had lower prices and shorter waiting times (table III). One explanation for the high price may have been that patients were admitted as inpatients rather than treated on a day care basis. However, the day care treatment price was high too. This suggests that the pricing structure of the ophthalmology service was crude. If the service was to remain competitive the additional consultant could not be funded through raising the price.

\section{What happened as a result of the internal market?}

During the ensuing negotiations concern and increasing dissatisfaction with the service was reported by general practitioners to purchasers. The fund holders in the neighbouring health district decided that they wanted to secure a better service immediately. They identified an undisclosed sum of money, and, working with their purchasing authority, drew up criteria for a better quality service and invited the local unit and other nearby ophthalmology units to tender for their contracts. The selection criteria covered the following features: $(a)$ compliance with service specifications and quality targets; $(b)$ track record and service development; $(c)$ the availability of specialist services; (d) training and staff development; (e) management of outpatient clinics; and $(f)$ satisfactory travel arrangements. As a result of this exercise the neighbouring district and its fundholders withdrew their contracts from the local unit for the contracting year 1992-3.

Theoretically the impact of these decisions on patients should have meant that those referred to the new unit would be seen more quickly but have to travel further for routine inpatient care. Others, referred from within the host district, would continue to receive care in the local unit, where the quality of service should improve because, with fewer patients to see, the clinicians would have longer to spend with each patient.

The impact of the decision was to threaten the viability of the local ophthalmology unit. Firstly, the local hospital lost up to $£ 250000$ in contracted work. Secondly, the cost per case for ophthalmic care within the hospital rose and was reflected in the price, making the service even less financially competitive. Thirdly, the department found it even more difficult to meet the College of Ophthalmologists' requirements for the training of junior doctors and the new rules on junior doctors' hours of work.

In practice the threat to the viability of the local unit quickly became apparent. But so too did the fact that, although the contracts from the neighbouring district were being withdrawn over a nine month period many patients from that district still kept coming to the local unit, many of them through the accident and emergency department. The unit was therefore still clinically under pressure, with the added problem of being financially threatened.

As the risk to the viability of the unit became clear (in a commercial setting would have been considered technically bankrupt) general practitioners in the host district, both fundholders and non-fundholders, pressed to retain a local service. If the local unit closed 
other neighbouring units did not have enough extra capacity to cope with the existing workload. As a result the host purchasing authority and the local fundholders agreed to put funds $(£ 80000)$ towards an extra consultant to maintain the viability of the service.

A locum consultant was appointed in October 1992. Waiting times for outpatient appointments subsequently dropped to less than 12 weeks, urgent cases were able to be seen on the day of referral, and general practitioners started describing the service as "excellent."

Central to this agreement between purchasers, general practitioners, and the local hospital has been a recognition that clear quality standards need to be set to ensure that the service meets the needs of patients in the most cost effective way. General practitioners have been involved in developing the service specifications (see box) and protocols for care, day surgery will increase, and a development project to measure the outcome of cataract surgery is already underway which will take on board the views of patients. This will allow purchasers, consultants, and general practitioners to focus their attention on what patients consider to be important.

In 1993 there is evidence that some of the contracts lost a year earlier will be regained, and the unit may win some new ones. The position remains uncertain. Ophthalmologists are in short supply. Many changes are happening to providers on the outskirts of London. Among the changes proposed is for a merger of the local hospital with one nearby.

\section{What lessons have been learnt?}

This case study highlights some real and new issues brought about by the NHS reforms. The internal market can help to resolve some complicated and longstanding problems relatively quickly, but caution is needed.

- Purchasers may make decisions based on unsophisticated activity and financial information without always realising the full and long term impact on valuable and essential services. Their desire to act entrepreneurially may also outstrip their ability, initially, to deliver their side of the contract: in this case the contracts moved but the patients kept coming.

- The assessment of the quality of care has focused on customer measures-for example, waiting timesrelying on the views of general practitioners as a proxy for patients' views, rather than patient based outcomes.

- Information systems for both finance and activity are not yet accurate enough to be able to support the requirements of either purchasers or providers.

More specifically, the recent recommendations made by the Chief Medical Officer's working group on specialist medical training endorse the decision to appoint an additional consultant ophthalmologist. ${ }^{15}$ There are, however, other models of care, ${ }^{16}$ for example primary care based services, which may need to be considered, particularly if the service is to be further developed in the future.

Some of the issues raised in this case study have already been highlighted, and concern has stimulated a debate about the need to manage the change which will be driven by the market, ${ }^{17}$ particularly in London. ${ }^{18}$ Perhaps, however, the most important message that should be shared from this case study is the importance

\section{Policy implications}

- The internal market can help to resolve some important and longstanding problems

- This case study suggests that caution is needed because decisions may be based on unsophisticated activity and financial information

- Information on the quality of care is also crude. Clinical outcome measures which include the views of patients need to be developed

- As a result of these limitations changes made to contracts may have unforeseen implications for related services

- One way to ensure that decisions are based on informed choice is to develop mechanisms to facilitate collaboration between purchasers and providers, including general practitioner fundholders

and benefit of working together. Collaboration between purchasers, including general practitioner fundholders, and providers, including clinicians, is essential to ensure that the objectives of securing better quality and choice for patients within the limited resources for health care are realised. One of the good results of this episode was the closer relation between the host district health authority and all its general practitioners, whether fundholders or not.

Whatever strategy is evolved for managing the internal market in future, there is a strong case for creating incentives to ensure that collaboration is not left to chance. One mechanism which may facilitate this process is that both purchasers (including general practitioner fundholders) and providers are accountable to a single agency for the decisions that they make. ${ }^{19}$

We thank all those general practitioners, hospital staff, and purchasers who have contributed to and supported this work.

1 National Association of Health Authorities and Trusts. The financial survey 1992. Birmingham: NAHAT, 1992.

2 NHS Management Executive. The NHS reforms: The first six months. London: HMSO, 1990 .

3 Salter B. The heart of the matter. Health Service foumal 1992;102:230-1.

4 Dobson J. DoH rethinks GP freedoms as two tier service merges. Health Service foumal 1993;103:3.

5 Office of Health Economics. Compendium of health statistics. 6th ed. London: OHE, 1987.

6 Kini MM, Leibowitz HM, Colton T, Nickerson RJ, Canley J, Dawber TR. Prevalence of senile cataract, diabetic retinopathy, senile macular degeneration and open angle glaucoma in the Framingham Eye Study. $A m \mathcal{F}$ tion and open angle glaucor

7 Podgor MJ, Leske MC, Ederer F. Incidence estimates for lens changes, macular changes, glaucoma and diabetic retinopathy. Am $\mathcal{f}$ Epidemiology 1983;118:206-12.

8 Harries U. Analyses of routinely collected data in relation to ophthalmology services. Study of visual disability and impaiment in older people. Manchester: Public Health Research and Resource Centre, Bolton, Salford, Trafford and Wigan Health Authorities, 1992

9 South East Thames Regional Health Authority. Public health and service development. Modelling the demand for acute services-ophthalmology. Bexley: SETRHA, 1991

10 Rosenthal RA. The demand for ophthalmic services. $B M F$ 1992;305:904-5.

11 Thomas H, Humphrey R. Day surgery for cataracts. $B M 7$ 1992;305:536-7.

12 College of Ophthalmologists. Hospital eye service. London: College of Ophthalmologists, 1991.

13 Audit Commission. A short cut to better services. Day surgery in England and Wales. London: Audit Commission, 1990.

14 Department of Health. The patient's charter. London: HMSO, 1991.

15 Department of Health. Hospital doctors: training for the future. London: DoH, 1993.

16 Dowie R. Patterns of hospital medical staffing: ophthalmology. London: HMSO, 1991.

17 Tomlin Z. Where angels fear to tread. Health Service fournal 1993;103:13.

18 Department of Health. Making London better. London: DoH, 1993.

$19 \mathrm{Ham}$ C. What future regions? BMF 1992;305:131-2.

(Accepted 2 October 1993) 